\title{
Investigation of Factors Affecting Medication Adherence Among People Living with HIV/AIDS under Non - Governmental Organizations in Senegal
}

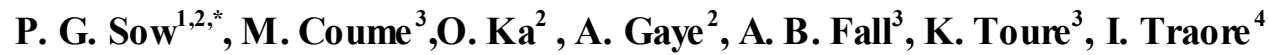 \\ ${ }^{1}$ Social institute of Health and hygiene of Dakar \\ ${ }^{2}$ University of Bambey \\ ${ }^{3}$ Cheikh AntaDiopUniversity of Dakar \\ ${ }^{4}$ Aristide le Dantec Hospital of Dakar- Bacteriology laboratory
}

\begin{abstract}
A ims:This prospective cross-sectional study was carried out to determine factors such as clinical and demographic variables that may affect medication adherence among people living with HIV/AIDS (PLWHA) receiving treatment at the Institute of health and hygiene of Dakar, but are affiliated to Non-Governmental Organizations which are HIV/AIDS support group based in Dakar..All consenting subjects from these two support groups were enrolled into study but 305 PLWHA volunteered to participate throughout the three months period of the study. Methods: The study was conducted with the aid of structured interview assisted questionnaires to obtain information on demographic characteristics such as age, sex, occupation, marital status, educational backgrounds, and source of support. Information on availability and side effects of antiretroviral drugs were also obtained. Results:This study indicated that majority of people living with HIV/AIDS interviewed were females $(80.3 \%)$ while $(19.7 \%)$ were males. Male respondents show better adherence $(91.7 \%)$ to ARV medications than female counterparts (83.7\%). Subjects in age the age groups $24-35$ years which is the most sexually active groups are more vulnerable (59.1\%) when compared to other age groups. A large number, $(67.2 \%)$ were married and there was a significant difference between marital status of PHWHA $(\mathrm{P}<0.05)$ and level of adherence to antiretroviral med ications. Descriptive and Chi-square statistical tests were used respectively to evaluate the distribution of respondent's opinion and investigate the level of association between the variables being consideredand respondent'sadherence to antiretroviral medications. Conclusion: We conclude that there is need to carry out further study in order to fully exp lore the extent to which marital status and other factors can affect medication adherence of people living with HIV/AIDS.
\end{abstract}

Keywords Antiretroviral (ARV), Medication Adherence, Variables, Non Govern mental Organization (NGO)

\section{Introduction}

Hu man Immunodeficiency Virus (HIV), the pathogen that causes Acquired Immune Syndrome (AIDS) has been the most significant emerging infectious agent in the last century and continually threatens to create health, social and developmental problems in this millennium, The virus is indeed a challenge to science and mankind[1]. Senegal has one of the Africa's lowest HIV/AIDS infection rates less than $2 \%$ but vulnerable groups such as sex workers have higher HIV prevalence. Currently [2], HIV infection among legal sex workers in Dakarhas risen to $21 \%$, co mpared to $1 \%$ 20 years ago. The rate is as high as $30 \%$ in the southern city of Ziguinchor[3]. The HIV prevalence for clandestine sex workers is not available; it thought to be much higher than

* Corresponding author: pgallo92000@yahoo.fr (P.G.Sow)

Published online at http://journal.sapub.org/phr

Copyright (C) 2012 Scientific \& Academic Publishing. All Rights Reserved the rate for registered sex workers. We estimate that more than $80 \%$ of Senegal sex workers do not register. Although it is one of the poorest countries in the world, with a per capita annual income less than $\$ 600$ in 2008, Senegal is considered one of the world's success stories in HIV prevention. While other sub-Saharan African countries are experiencing the worst epidemic in the world. W ith a "concentrated" epidemi $c$, the general population in Senegal has remained relatively free of AIDS, through vulnerab le populations have significa ntly higher prevalence among commercial sex workers. Senegal' success at maintaining low overall prevalence has been attributed to the confluence of a number of factors, including strong political leadership, early involvement and leadership among religious leaders, conservative cultural norms regarding sexual practices, anda comprehensivestrate gic approach implemented early in the epidemic[4]The degree of government commitment in the fight against AIDS is visible in its well developed public sector ART program, the Initiative Senegalese ARV Access[5].

Presently, HIV and AIDS threaten the very gain made by 
man in medicine and have been reported virtually among all racial, ethnic, age and socioeconomic groups, in every urban and most rural communities in sub-Saharan Africa. Initially identified as a diseases among men who have sex with men, the current AIDS epidemic now comprises diverse multip le sub-epidemics that vary not only by region and community, but also by population, risk behaviour, geography and HIV serotypes [6-7].

The first AIDS case in Senegal was reported in 1986, putting the period of introduction of HIV infection into Senegal around late 1970 s to early 1980 s. Since then the epidemic has steadily grown. The adult prevalence has increased from $1.8 \%$ in 1991 to $4.5 \%$ in 1996 and $5.8 \%$ in 2001, and the estimated 7.5 to $8.3 \%$ in 2003. Estimate using the HIV/Syphilis zero-prevalence sentinel surveyamong women attending antenatal clinic indicates that more than 100000 Senegaleses were infected with the virus by the end of 2001 [8-9]. The epidemic in Senegal has extended beyond the commonly classified high risk groups and is now common in general population. HIV affects all age groups but youth between the ages of 20-29 years are most affected[10]. AIDS have responded poorly to conventional biomedical and public health solutions because of the complexity and the unique features of the infectious virus[11]. Up till now, there is no effective cure for HIV/AIDS and vaccines, even if promising are still in the trial stages, but drug management in correct combinations are available. In recent times, there have been significant breakthroughs in the effectiveness of AIDStreatment through the introduction of Highly Active Antiretroviral Therapy (HAART) which provide the possibility of significantly controlling the HIV[12]. The drugs combinations include combination of two nucleoside reverse transcriptase inhibitors such as stavudine, lamivudine and one non-nucleoside reverse transriptase inhibitor such as Nevirapine. Combination of two nucleoside reverse transcriptase inhibitors and one protease inhibitor[13]. These antiretroviral drug combinations are available at various designated ARV clin ics set up by theGovernment of Senegal across the country.

However, since people livings with HIV/AIDS (PLWHA) have make this complex antiretroviral drug regimen usually on daily basis, adherence to these drugs are challenging[14].In a clinical trial, the HAART treatment resulted in low or undectable viral load levels in as much as $85 \%$ of the patients. The laboratory investigations and the real world of AIDS treatment, only $50 \%$ of patients were positively affected by the HAART treatment[15]. The explanation for this alarming disparity of result has been adduced to poor adherence to HAART regimens. Despite the fact that AIDS is a very complex disease, patients simply do not recognize the importance of adhering to the medication regimen[16]. Some believe that the negative side effect of AIDS medication outweighs the life lengthening effects and may decide to discontinue treatment[15]. Evidence shows that there is dearth of information on certain demographic and clinical variab les that may hinder or improve the level of adherence of people living with HIV/ AIDS in developing countries like Senegal.

\section{Methodology}

The criteria for selection of eligible respondents were based on the subjects attending antiretroviral (ARV) clinic, Institute of health and hygiene of Dakar affiliated to the support groups PLWHA. Subjects older than or equal to 18 years of age, conscious and who gave their informed consent to participate voluntarily in the study. Subjects that were not receiving drug treatment atantiretroviral clinic were excluded from the study. In order to encourage frank revelation about potentially sensitive matters, names were not recorded and respondents were assured that their responses would be kept confidential.

The study was prospective cross-sectional in design which involved the use of structured interview assistedquestionnai res containing both open- and closed-ended questions. Subjects were properly briefed on the objectives of the study and benefit that can later be obtained from the study.

The questionnaire was pre-tested using a team of experts consisting of three experienced physicians and two experience pharmacists specialized in antiretroviral drug therapy to assess the content. PLWHA that met the inclusion criteria were interviewed between November, 2011 and January, 2012 with the aid of structured questionnaires designed to obtain information on socio-demographic characteristics; age, sex, occupational status, marital status, source of support, educational background among other relevant questions.

Information on some clinical variables such as side effects and availability of antiretroviral drugs were also obtained. Three hundred and five (305) subjects consented to participate in the study within the three months period. Each respondent used to collect five $\$$ as transport fare to study centre and were giving five ten $\$$ as mobilization fee for the interview.

Data generated from the responses of the subjects interviewed were treated confidentially and were subjected to SPSS window version 10.0 for data analysis. Findings were presented using descriptive statistics such as frequency, percentages, and averages to evaluate the distribution of respondents' opinion. Chi square statistical test at $5 \%$ level of significance was used to investigate the extent of association between some of the variables considered and respondent adherence to ARV medications.

\section{Results}

Sixty (60) (19.7\%) people living with HIV/AIDs interviewed were male with mean age of 40 years and 245 $(80.3 \%)$ were females with mean age of 34.5 years (Table 1 ). However, chi square statistical test showed that there was no significant difference on the level of adherence to ARV medications between male and female respondents $(\mathrm{P}>0.05)$, 
but male seemed to adhere better $(91.7 \%)$ than their female counterpart (83.7\%). (See Table 2)

Table 1. Demographic Characteristics of Respondents

\begin{tabular}{|c|c|}
\hline Variables/Characteristics & Number $(\%) \mathrm{N}=61$ \\
\hline \multicolumn{2}{|c|}{ Age Distribution (years) } \\
\hline $24-35$ & $180(59.1)$ \\
\hline $36-45$ & $95(31.1)$ \\
\hline 46 and above & $30(9.8)$ \\
\hline \multicolumn{2}{|c|}{ Sex Distribution } \\
\hline Male & $60(19.7)$ \\
\hline Female & $245(80.3)$ \\
\hline \multicolumn{2}{|c|}{ Education Attainment } \\
\hline No formal education/illiterate & $30(9.8)$ \\
\hline Primary & $65(21.3)$ \\
\hline Secondary & $140(45.9)$ \\
\hline Tert iary & $70(23.0)$ \\
\hline \multicolumn{2}{|c|}{ Occupational status } \\
\hline Unemployed & $15(4.9)$ \\
\hline Unskilled & $135(44.3)$ \\
\hline Skilled & $75(24.6)$ \\
\hline Professional & $80(26.2)$ \\
\hline \multicolumn{2}{|c|}{ Marital Status } \\
\hline Single & $65(21.3)$ \\
\hline Married & $205(67.2)$ \\
\hline Divorce & $5(1.6)$ \\
\hline Widow & $30(9.8)$ \\
\hline \multicolumn{2}{|c|}{ Source of Support/Finance } \\
\hline Self reliance & $250(81.9)$ \\
\hline Family support & $45(14.8)$ \\
\hline Non-governmental Organization & $10(3.3)$ \\
\hline
\end{tabular}

Majority, 140 (45.9\%) had secondary education, 70 $(23.0 \%)$ had post secondary or tertiary education while 65 $(21.3 \%)$ and $30(9.8 \%)$ had primary and no formal education respectively. This study, however, showed that there was no association between the educational status of PLWHA and their adherence to medications ( $p>0.05 \%)$, but subjects with at least a minimum of elementary education complied better to ARV med ications; (secondary $89.3 \%$ and primary $84.6 \%$ ), than those with no formal education (66.7\%) (Table 2). Greater proportions of respondents with no formal education were wo men $20(66.7 \%)$.

A large number, $135(44.3 \%)$ belonged to the unskilled labour, $75(24.6 \%)$ and $80(26.2 \%)$ were skilled workforce and professional respectively. The remain ing 15 (4.9\%) were unemployed (Table 1). Occupational status was shown to have effects adherence to ARV medications. PLWHA in skilled labour adhered better (93.3\%) than professionals $(87.5 \%)$ and the unskilled $(81.5 \%)$ respectively. The least level of adherence was a mong the unemployed respondents. There was however, no significance difference between occupation status of PLWHA and adherence to medications $(\mathrm{P}>0.05)$. ( Table 2) This study showed that a substantial number of HIV positive patients interviewed were married $205(67.2 \%)$ while, $65(21.5 \%)$ were singles, widowed and divorced constitute $30(9.8 \%)$ and $5(1.6 \%)$ respectively. (Table 1) A statistical significance relationship however exists between marital status and adherence to ARV medications. Respondents who are singles tend to complied better $(92.3 \%)$ than other groups (married $87.8 \%$, widowed
66.7\%) (Table 2). Marital status could therefore be a demographic characteristic of PLWHA that can affect adherence to ARV medications, though this factor needs to be investigated further through a study with a larger sample size.

Table 2. Effect of demographic variables of PLWHA on the level of adherence to ARV medications

\begin{tabular}{|c|c|c|c|c|}
\hline Variables & $\begin{array}{c}\text { YES (Non } \\
\text { adherence) } \\
\mathrm{N}(\%)\end{array}$ & $\begin{array}{c}\mathrm{NO} \\
\text { (Adherence) } \\
\mathrm{N}(\%)\end{array}$ & P-value & Remark \\
\hline \multicolumn{5}{|c|}{ Age distribution (years) } \\
\hline $24-35$ & $10(13.9)$ & $155(86.1)$ & \multirow{3}{*}{0.973} & \multirow{4}{*}{$\begin{array}{c}\text { Not } \\
\text { significant }\end{array}$} \\
\hline $36-45$ & $15(15.8)$ & $80(84.2)$ & & \\
\hline$>46$ & $5(16.7)$ & $25(83.3)$ & & \\
\hline \multicolumn{4}{|c|}{ Sex distribution } & \\
\hline $\begin{array}{l}\text { Male } \\
\text { Female }\end{array}$ & $\begin{array}{c}5(8.3) \\
40(16.3)\end{array}$ & $\begin{array}{c}55(91.7) \\
205(83.7)\end{array}$ & 0.484 & $\begin{array}{c}\text { Not } \\
\text { significant }\end{array}$ \\
\hline \multicolumn{5}{|c|}{ Education background } \\
\hline $\begin{array}{l}\text { No formal } \\
\text { education } \\
\text { Primary } \\
\text { Secondary } \\
\text { Tert iary }\end{array}$ & $\begin{array}{l}10(33.3) \\
10(15.4) \\
15(10.7) \\
10(14.3)\end{array}$ & $\begin{array}{c}20(66.7) \\
55(84.6) \\
125(89.3) \\
60(85.7)\end{array}$ & 0.569 & $\begin{array}{c}\text { Not } \\
\text { significant }\end{array}$ \\
\hline \multicolumn{5}{|c|}{ Occupational status } \\
\hline Unemployed & $5(33.3)$ & $10(60.7)$ & & \\
\hline Unskilled & $25(18.5)$ & $110(81.5)$ & \multirow{3}{*}{0.578} & \multirow{4}{*}{$\begin{array}{c}\text { Not } \\
\text { significant }\end{array}$} \\
\hline Skilled & $5(6.7)$ & $70(93.3)$ & & \\
\hline Professional & $10(12.5)$ & $70(87.5)$ & & \\
\hline \multicolumn{4}{|c|}{ Marital status } & \\
\hline Single & $5(7.7)$ & $60(92.3)$ & \multirow{5}{*}{$* 0.043$} & \multirow{5}{*}{$\begin{array}{c}* \\
\text { Significan }\end{array}$} \\
\hline Married & $25(12.2)$ & $180(87.8)$ & & \\
\hline Divorced & $5(100.0)$ & - & & \\
\hline Widow & $10(33.3)$ & $20(66.7)$ & & \\
\hline \multirow{2}{*}{\multicolumn{5}{|c|}{ Financial stat us }} \\
\hline & & & & \\
\hline $\begin{array}{l}\text { Family } \\
\text { support } \\
\text { Non } \\
\text { government } \\
\text { organization }\end{array}$ & $\begin{array}{c}35(14.0) \\
10(22.2) \\
-\end{array}$ & $\begin{array}{c}215(86.0) \\
35(77.8) \\
10(100.0)\end{array}$ & 0.681 & $\begin{array}{c}\text { Not } \\
\text { significant }\end{array}$ \\
\hline
\end{tabular}

Opinion of respondents on the source of support for the procurement of antiretroviral drugs show that a large number, $250(81.9 \%)$ source for their drugs through self effort, 45 $(14.8 \%)$ and $10(3.3 \%)$ depended on family and non-governmental organizations respectively. There was however no association between source of financial support and adherence to ARV medications $(\mathrm{P}>0.05)$, but respondents that relied on NGOs for support complied better $(100 \%)$ than those that depended on self $(86.0 \%)$ and family (77.8\%) respectively.( Table 2 )

Self report of adherence by respondents indicate that 230 (75.4\%) comply with the prescribed ARV medications irrespective of the drug side effects while 75 (24.6\%) did not comply with their medications once side effects of the drugs begin to manifest.

A substantial number of respondents 290 (95.1\%) claimed that availability of antiretroviral drugs has a lot of influence on adherence to medication. But for Senegalese government 
initiative of making antiretroviral drugs available at a highly subsidized rate in the designated ARV clinic across the country, the level of adherence has improved.

\section{Discussion}

This study confirmed that HIV/AID is a disease that is not restricted to a particular gender but may affect both male and female populations. Female respondents were more affected than the male counterpart. This is in agreement with previous studies which reported that HIV prevalence is higher among females[9].

HIV/AID affect all age groups in the population with the most sexually active group (24-35years) being more vulnerable than other ages. This is in agreement with the report of a survey conducted by theMinistry of Health,Senegal which reported that this disease is more common among the youth in their productive years [9].

In addition, this study showed that HIV and AIDS affect people irrespective of their educational status but PLWHA with no formal education constitute the least probably because few respondents from this category were available for interview. Respondents with at least a minimum of elementary education complied better to antiretroviral medications than those with no formal education. The low level of adherence among this group of people living with HIV/AIDSmay be due to low level of awareness as a result of lack of formal education, but there was no statistically significant difference between educational background of PLWHA and adherence to ARV medications probably because of Government initiative of making antiretroviral drugs accessible and affordable for people living with HIV/AIDS in the country irrespective of educational status.

A large number of HIV positive patients interviewed were married (Table 1) and this is contrary to previous study conducted, which reported that HIV prevalence was higher among singles when compared to those married[9]. However,Government through National Agency for the Control of AIDSin Dakar need to intensify efforts in enlightening the married men and women on the risk factors that can predisposeone to the disease rather than focusing only on the youth and singles. It was however noted that there was a statistical significant difference between marital status and adherence to antiretroviral medications ( Table 2). Higher adherence among PLWHA who are singles may be due to the fact that they are looking up to the future with full expectation that complying with prescribed ARV medications will make them to have a normal life, get married and possibly have their own children.

In general, adherence of respondents from this study seems to be relatively high ( $>50 \%)$ irrespective of age, sex, educational attainment, occupation, financial status, side effects and availability of drugs among other variables considered. Higher adherence may be as a result of effort of Senegalese Government.in the creating awareness and enlightening people on the realities of HIV and AIDS.
Occupation of respondents was shown to have effect on adherence to ARV medications (Table 2). Least level of adherence among unemployed (60.7\%) may be due to the fact that this group still finds it difficult to pay the sumof one thous and CFA being charged monthly for the replenishment of their ARV medications $(\mathrm{P}>0.05)$.It is therefore recommended that government should endeavor to continue this subsidy measure to even a substantially lower rate than it is at present so as to enhance adherence of people living with HIV/AIDS to medication and reinforce their confidence that they can live normal life once they have access to their drugs and at affordable price.

\section{Conclusions}

Fro $m$ the present study, it can be conducted that HIV and AIDS is a disease that can affect anybody regardless of age, sex, financial and occupational status, marital status, educational background among other variables.However, marital status of PLWHA seems to have a significance influence on adherence to ARV medications. Further study need to be carried out in order to fully exp lore the impact of maritalstatus and other variables on medication adherence of people living with HIV and AIDS in Dakar.It is against this background that this study intended to investigate the clinical and demographic variables of people living with HIV/AIDS that may affect adherence to HAART regimens. Findings from this study are expected to assist HIV positive patients the importance of therapeutic adherence. The objective of this study was to investigate the factor affecting medication adherence among people living with HIV/AIDS with the goal of providing and promoting pharmaceutical care.In addition, this study corroborates the fact that adherence of PLWHA is heavily dependent on availability of antiretroviral drugs as well as financial capacity of the patient, but there was no significant difference between these variables and respondent adherence. It is interesting to note that, during the course of the interview some respondents $5(8.2 \%)$ confirmed that sometimes when ARV drugs were not available at ARV clinics, they did not take any drugs for about one month simply because these drugs were not readily available elsewhere. As at the time of this study, respondents said that were getting their medications regularly. This has led to imp rovement in their adherence.

Majority, (75.4\%) usually adhere to prescribed ARV medication irrespective of experienced side effects. This high compliance may be due to respondents' recognition of their disease as a terminal illness and failure to co mp ly with prescribed ARV medications may lead to premature death.

\section{ACKNOWLEDGMENTS}

We hereby acknowledge thestaff in charge of H.I. V/AIDS patients, the Family and the Senegalese based non-governmental organizations notable for the care and 
support of people living with HIV/AIDs, for their cooperation and support during the course of this study.

\section{REFERENCES}

[1] Soyinka F.(1998) Need assessment and care programme for people living with HIV/AIDS in resource constrained and hostile environment. IntConf AIDS 1998; 12: 98. Abstract no. 12424.

[2] UNAIDS/WHO(2010) Working Group on Global HIV/AIDS surveillance.

[3] Senegal Epidemiological fact sheet $N^{\circ} 11$, September 2004

[4] UNAIDS/WHO. Epidemiological fact sheets on HIV/AIDS and sexually transmitted infections: up date 2009.

[5] UNAIDS/WHO (2009 February), "UNAIDS guidance note on HIV and sex worker"

[6] AyodejiAkala, F., Abu-Raddad, L., Semini, I., Riedner, G., Wilson, D. ,Tawil, O. (2008) Characterizing the HIV/AIDS epidemic in the Middle East and North Africa: evidenceon levels, distribution and trends - time for strategic action. . Middle East and North Africa HIV/AIDS Epidemiology Synthesis Project.

[7] UNAIDS/WHO(2010) Epidemiological Update, Sero-sentin el Report for Africa .

[8] UNAIDS/WHO Report on the global AIDS Epidemic, May 2010
[9] Eshrati, B., Asl, R. T., Dell, C. A., Afshar, P., Millson, P. M., Kamali, M. , Weekes, J. (2008) Preventing HIV transmission among Iranian prisoners: Initial support for providing education on the benefits of harm reduction practices. Harm Reduct J, 5, 2

[10] Ministry of Health and Prevention(2004).HIV/Syphilis Sentinel Seroprevalence Survey in Senegal . National AIDS and STDs control programme,

[11] Blakeslee D.(1998).adherence to therapy . JAMA HIV/AIDS 1998.

[12] Brown T., Salomon, J. A., Akena, L., Raftery, A. E, Gouws, E. (2008) Progress and challenges in modelling country-level HIV/AIDS epidemics: the UNAIDS Estimation and Projection Package. Sex Transm Infect, 1, 5-10.

[13] Dejong, J., Jawad, R., Mortagy, I, Shepard, B. (2005) The sexual and reproductive health of young people in the Arab countries and Iran. Reprod Health Matters, 15, 49-59.

[14] Sarna A, Pujari S, Sen gar AK, Garg R, Gupta I, Dam J.(2008) Adherence to antiretroviraltherapy and its determinants amongst HIV patients in India. Indian $\mathrm{J}$ Med Res.;127(1):28-36.

[15] Darbes L, Crepaz N, Lyles C (2008). The efficacy of behavioral interventions in reducing HIV risk behaviors and incident sexually transmitted diseases in heterosexual African Americans. AIDS ;22:1177-1194.

[16] Chiao C, Morisky DE, Ksobiech K, Malow RM (2009). Promoting HIV testing and condom use among Filipina commercial sex workers: findings from a quasi-experimental intervention study. AIDS Behav .13(5):892-901. 